\title{
Diffusion-weighted MR Imaging in the Mandible
}

\author{
Yusuke Sasaki
}

Nihon University Graduate School of Dentistry at Matsudo, Radiology, Matsudo, Chiba 271-8587, Japan

Correspondence to :

Yusuke Sasaki

E-mail : mayu08005@g.nihon-u.ac.jp

Keywords :

MRI, diffusion, ADC, mandible, nor-

mal

\begin{abstract}
Few studies have concerned the absolute apparent diffusion coefficient (ADC) values in the normal mandibular bone marrow on diffusionweighed images. Purpose of this study was to determine the average of $\mathrm{ADC}$ values in the region of the normal mandibular bone marrow and to establish reference values of the absolute ADC values for further studies. Subjects (7 men and 13 women) with normal mandible were chosen ; age 20-69 years old (mean, 34.7). All subjects were examined with MR imaging, including panoramic radiographs and diffusionweighted imaging with two $\mathrm{b}^{-}$values $\left(0\right.$ and $\left.1,000 \mathrm{~s} / \mathrm{mm}^{2}\right)$ at $1.5 \mathrm{~T}$. ADC values were determined in regions of mandibular bone marrow from lower first premolar to lower second molar without mandibular canal and tooth roots. ADC values were mean in $0.972 \times 10^{-3} \mathrm{~mm}^{2} / \mathrm{s}$, highest in $1.24 \times 10^{-3} \mathrm{~mm}^{2} / \mathrm{s}$, and lowest in $0.779 \times 10^{-3} \mathrm{~mm}^{2} / \mathrm{s}$. The ADC values can be used for reference in future studies and in clinical settings.
\end{abstract}

\section{Introduction}

Diagnostic imaging of the maxillofacial region has been performed primarily through conventional radiography including intraoral periapical radiography, occlusal radiography, panoramic radiography, $\mathrm{x}$-ray computed tomography (CT), and bone scintigraphy utilizing radiation. More recently, magnetic resonance (MR) imaging has been applied to the maxillofacial region, enabling direct visualization of the soft tissue and the bone marrow which is difficult to be visualized through conventional $\mathrm{x}$-ray modalities (1). However, according to Gonzalez et al. (2) for the Japan suggest that $3.2 \%$ of cancers could be caused by CT examination. Therefore, MR imaging without the radiation exposure is useful for an imaging diagnosis. According to the some reports (3-7), Diffusion -weighted MR imaging (DWI) reveals ischemic regions in the brain within minutes after the induction of focal ischemia in experimental stroke and as soon as a patient with acute stroke is available for imaging studies. DWI has become an essential part of the imaging examination of patients with hyper acute stroke (3). DWI is based on the random translational movement of water molecules in biologic media (3). In late years, the apparent diffusion coefficient (ADC) values and diffusion-weighted images are applied to a diagnosis in various regions (4-18).

The net diffusion of the molecules is referred to as ADC. Because the cellular structures are distributed anisotropically, the measurement of diffusion is direction dependent; Diffusion weighting is expressed with a $b^{-}$value, which is dependent on sequence characteristics (3).

The $\mathrm{b}^{-}$-value increases with increasing diffusion weighting, and sufficient diffusion weighting is usually achieved with a $\mathrm{b}^{-}$value of $1,000 \mathrm{~s} / \mathrm{mm}^{2}$. The $\mathrm{ADC}$ value can be calculated as the slope of the natural logarithm of the signal intensity versus the $b$ -value. Two-point ADC estimates, with $b=0$ and $b=$ $1,000 \mathrm{~s} / \mathrm{mm}^{2}$, are adequate for measuring diffusion in the mandibular marrow. However, there has been no report concerning the usefulness to determine the average of $\mathrm{ADC}$ values in the region of the normal mandibular bone marrow.

The purpose of this study was to determine the average of $\mathrm{ADC}$ values in the region of the normal mandibular bone marrow and to establish reference values of the absolute ADC values for further studies. 


\section{Subjects and Methods}

The normal studies using diffusion weighted images of mandible were 20 patients with no abnormal findings on panoramic radiographs and STIR MR images, no history of radiotherapy, no severe periodontal disease, and no systemic diseases such as blood disease. The study subjects were selected from 1,000 patients who underwent MR imaging as outpatients in our department at the Hospital of Nihon University School of Dentistry at Matsudo between May and November 2011. These healthy subjects (7 men, 13 women) ranged from 20 to 69 years of age (mean, 34.7 years \pm 13.5 ; men, 28.3 years \pm 18.3 ; women, 39.6 years \pm 14.2 ). Diffusion-weighted imaging with sensitivity encoding (SENSE) technique consisted of scanning transverse to the axis of the mandibular body by using a $1.5 \mathrm{~T}$ MR scanner (Intera Achieva 1.5 T : Philips Medical Systems, Best, Netherlands) and with Cardiac coils. Diffusion-weighted study conditions were set as follows: TR 5106.33 $\mathrm{ms}$; TE $68.87 \mathrm{~ms}$; slice thickness, $6 \mathrm{~mm}$; matrix, $256 \times 256$; field of view, $250 \times 250 \mathrm{~mm}$; and 1 acquisition. The STIR imaging technique consist of TR 2,500 ms ; TE $60 \mathrm{~ms}$; slice thickness, $6 \mathrm{~mm}$; matrix, $256 \times 256$; field of view, $230 \times 230 \mathrm{~mm}$; and 1 acquisition. All MR images viewing were done in a quiet darkroom with a high definition display. Viewing time was kept to approximately 30 seconds at a viewing distance of approximately $40 \mathrm{~cm}$. In evaluation, each of the 2 radiologists made an individual assessment. If the assigned evaluation differed, the radiologists reached the final scoring by consensus.

The normal STIR images of mandible baseline structures adopted for the evaluation of MR signal intensity were cerebrospinal fluid (high signal intensity), muscle (intermediate signal intensity), and fat (low signal intensity).
ADC map was made on MRI console. The regions of interest (ROIs) were manually drawn on the ADC map on which the mandibular bone marrow from lower first premolar to lower second molar without mandibular canal and tooth roots.

The mean scores thus assigned were statistically analyzed for ADC values of men and women. The statistical software used was Stat View-J 5.0 (Abacus Concepts, Inc., Berkeley, CA), and Mann Whitney's U-test was carried out. This study was approved by the Ethics Committee of Nihon University School of Dentistry at Matsudo (EC02-023).

\section{Results}

All on STIR images of normal subjects, mandibular bone marrow demonstrated low signal intensity (100\%) (Fig. 1). All on DWI of normal subjects $(b=0)$, mandibular bone marrow demonstrated low to intermediate signal intensity (100\%) (Fig. 2). All on DWI of normal subjects $(b=1,000)$, mandibular bone marrow demonstrated low signal intensity (100\%) (Fig. 3). These results were not different in signal intensity of each image.

Table 1 was summarized $\mathrm{ADC}$ values and ROI area. On DWI, the mean $\mathrm{ADC}$ values were $0.972 \pm$ $0.170 \times 10^{-3} \mathrm{~mm}^{2} / \mathrm{s} \quad\left(\operatorname{Max} 1.24 \times 10^{-3} \mathrm{~mm}^{2} / \mathrm{s}\right.$, Min $\left.0.779 \times 10^{-3} \mathrm{~mm}^{2} / \mathrm{s}\right)$. The mean $\mathrm{ADC}$ values of men

Table 1. Mean and SD of ADC values with mean and $\mathrm{SD}$ of $\mathrm{ROI}$ area for mandibular bone marrow

\begin{tabular}{ccccc}
\hline & \multicolumn{2}{c}{$\begin{array}{c}\text { ADC } \\
\left(\times 10^{-3} \mathrm{~mm}^{2} / \mathrm{s}\right)\end{array}$} & \multicolumn{2}{c}{$\begin{array}{c}\text { ROI } \\
\left(\mathrm{mm}^{2}\right)\end{array}$} \\
\cline { 2 - 6 } & Mean & SD & Mean & SD \\
\hline Men and women $(\mathrm{n}=20)$ & 0.972 & 0.170 & 63.62 & 23.39 \\
Men $(\mathrm{n}=7)$ & 0.992 & 0.177 & 73.75 & 17.96 \\
Women $(\mathrm{n}=13)$ & 0.951 & 0.156 & 58.17 & 24.14 \\
\hline
\end{tabular}

Table 2. Mean ADC values and ROI area

\begin{tabular}{cccccc}
\hline $\begin{array}{c}\text { Nunber of } \\
\text { patients }\end{array}$ & $\begin{array}{c}\text { Mean ADC value } \\
\left(\times 10^{-3} \mathrm{~mm}^{2} / \mathrm{s}\right)\end{array}$ & $\begin{array}{c}\text { Mean SD of } \\
\text { ADC value } \\
\left(\times 10^{-3} \mathrm{~mm}^{2} / \mathrm{s}\right)\end{array}$ & $\begin{array}{c}\text { Mean of ADC } \\
\text { values of men } \\
\left(\times 10^{-3} \mathrm{~mm}^{2} / \mathrm{s}\right)\end{array}$ & $\begin{array}{c}\text { Mean of ADC } \\
\text { values of women } \\
\left(\times 10^{-3} \mathrm{~mm}^{2} / \mathrm{s}\right)\end{array}$ & $\begin{array}{c}\text { Mean ROI } \\
\left(\mathrm{mm}^{2}\right)\end{array}$ \\
\hline $\mathrm{n}=20$ & 0.965 & 190.91 & 0.992 & 0.951 & 62.08 \\
\hline
\end{tabular}




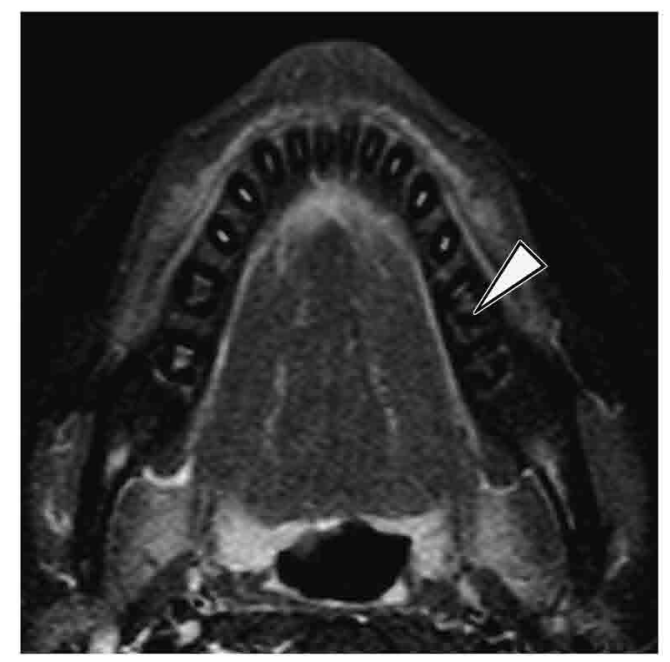

Fig. 1

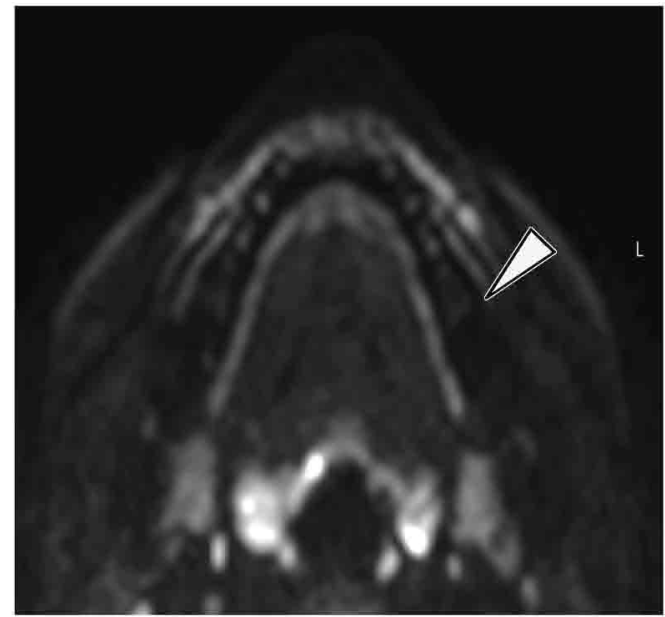

Fig. 3

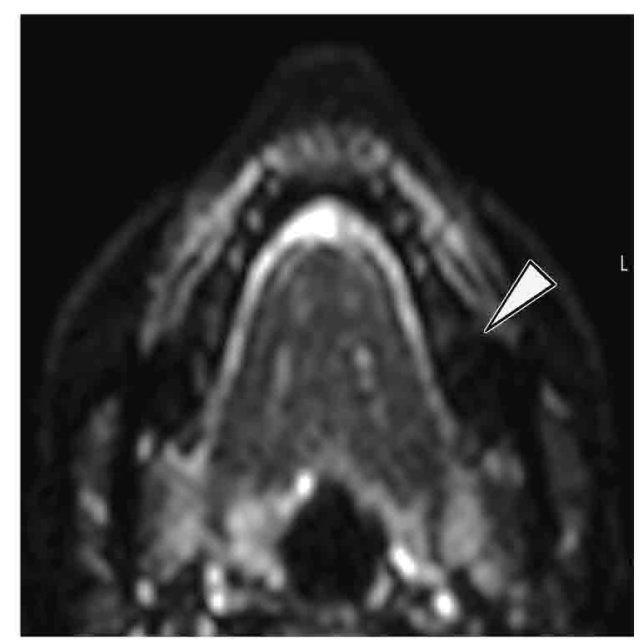

Fig. 2

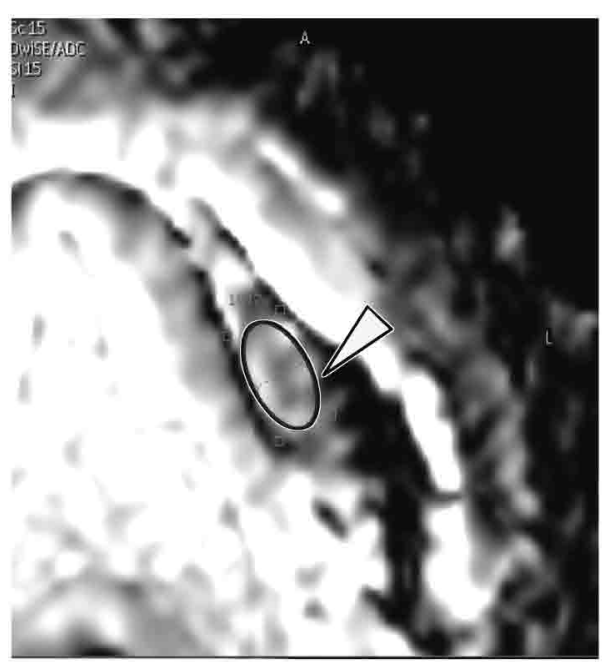

Fig. 4

Fig. 1. Axial STIR MR image shows low signal intensity in left side of the mandibular bone marrow (arrow head).

Fig. 2. Axial diffusion-weighted MR image $(b=0)$ shows low to intermediate signal intensity in left side of the mandibular bone marrow (arrow head).

Fig. 3. Axial diffusion-weighted MR image $(b=1,000)$ shows low signal intensity in left side of the mandibular bone marrow (arrow head).

Fig. 4. Axial ADC map shows in left side of the mandibular bone marrow on Region of Interest (ROI) (arrow head).

were $0.992 \pm 0.177 \times 10^{-3} \mathrm{~mm}^{2} / \mathrm{s}$ and of women were $0.951 \pm 0.156 \times 10^{-3} \mathrm{~mm}^{2} / \mathrm{s}$. No differences were observed between the ADC values in the men and those of the women $(\mathrm{P}>0.05)$. The mean ROI area was $63.62 \pm$ $23.39 \mathrm{~mm}^{2}\left(\operatorname{Max} 99.18 \mathrm{~mm}^{2}\right.$, Min $\left.30.52 \mathrm{~mm}^{2}\right)$. As for the size of ROI area, there was difference in up to
$69.34 \mathrm{~mm}^{2}$. The age value of women was higher than the value of men.

\section{Discussion}

Diffusion-weighted MR imaging reveals ischemic regions in the brain within minutes after the induc- 
tion of focal ischemia in experimental stroke and as soon as a patient with acute stroke is available for imaging studies (3). However, there has been no report concerning the usefulness to determine the average of ADC values in the region of the normal mandibular bone marrow. In this study, on STIR images, the mandibular bone marrow demonstrated low signal intensities in all subjects. These results accorded with a past report (1), therefore, it was thought that the mandibular bone marrow was normal. On diffusion-weighted images $(b=0)$, the mandibular bone marrow demonstrated low to intermediate signal intensities in all subjects. It is thought that some signal intensity rose as for these results by being affected by the perfusion. On diffusion-weighted images $(b=1,000)$, the mandibular bone marrow demonstrated low signal intensities in all subjects. The normal mandibular bone marrow signal intensity in DWI $(b=1,000)$ resulted to be a low signal intensity. Sumi et al. (8), reported that diffusion seemed to be influenced by "physical" parameters such as temperature, pressure, and viscosity. Furthermore, physiologic parameters can also influence diffusion; these are most significant because extracellular matrices and fluids are of great importance in the clinical context. The physiologic parameters include cellularity, amount and ratio of intracellular and extracellular water, nucleus-tocytoplasm ratio, and vascularity. Significant changes in any of these parameters may result in changes in the pixel intensity of the diffusion-weighted sequence. If we use adequately high $\mathrm{b}^{-}$values to eliminate signals from the vascular space $(b=1,000)$, then the signal intensity would originate solely from intracellular and extracellular water (3). In the whole brain, the mean ADC values were $0.89 \times 10^{-3} \mathrm{~mm}^{2} / \mathrm{s}$ in the cortical gray matter, $0.70 \times 10^{-3} \mathrm{~mm}^{2} / \mathrm{s}$ in the white matter (3). Baur, et al (10), reported that the mean ADC value for normal thoracic vertebral body bone marrow was $1.5 \times 10^{-3} \mathrm{~mm}^{2} / \mathrm{s}$. The present study revealed that the ADC values of the mandibular bone marrow was lower than thoracic vertebral body bone marrow and more highly than a brain. As for this, the mandibular marrow contents were thinner than the nerve cell density of the brain, and it was thought that the diffusion of the water molecule was high. No differences were observed between the ADC values in the men and those of the women $(\mathrm{P}>0.05)$.

In recent years, MR imaging has been applied noninvasively to the clinical imaging of bone marrow status. STIR imaging suppresses the fat signal within bone marrow and enhances small amounts of water, making this technique extremely useful for bone marrow imaging (3). However, the quantification by the numerical value was not possible.

Absolute ADC values may be used to identify the inflammatory tissue precisely, but their use requires a normal reference value for mandibular marrow region. Quantitative methods, with absolute ADC values for healthy and pathologic structures, are important when focal and diffuse abnormalities are suspected, because minor changes may be difficult to detect by visual inspection. In the present study, we were able to determine to ADC values of the mandibular marrow.

In conclusion, the $\mathrm{ADC}$ values can be used for reference in future studies and in clinical settings.

\section{References}

1. Lee K, Kaneda T, Mori S, Minami M, Motohashi J, Yamashiro M: Magnetic resonance imaging of normal and osteomyelitis in the mandible: Assessment of short inversion time inversion recovery sequence. Oral Surg Oral Med Oral Pathol Oral Radiol Endod, 96 : 499-507, 2003.

2. Berrington de GA, Darby S: Risk of cancer from diagnostic X-rays: estimates for the UK and 14 other countries. Lancet, 363 : 345-351, 2004.

3. Helenius J, Soinne L, Perkio J, Salonen O, Kangasmaki A, Markku K: Diffusion-Weighted MR Imaging in Normal Human Brains in Various Age Groups. Am J Neuroradiol, 23 : 194-199, 2002.

4. Meyer JR, Gutierrez A, Mock B, Hebron D, Prager JM, Gorey MT, Homer D : High- ${ }^{-}{ }^{-}$value diffusionweighted MR imaging of suspected brain infarction. Am J Neuroradiol, 21: 1821-1829, 2000.

5. Stadnik TW, Chaskis C, Michotte A, M Shabana W, Rompaey K, Luypaert R, Budinsky L, Jellus V, Osteaux M: Diffusion-weighted MR imaging of intracerebral masses: comparison with conventional MR imaging and histologic findings. Am J Neuror- 
adiol, 22 : 969-976, 2001.

6. Tievsky AL, Ptak T, Farkas J : Investigation of apparent diffusion coefficient and diffusion tensor anisotropy in acute and chronic multiple sclerosis lesions. Am J Neuroradiol, 20 : 1491-1499, 1999.

7. Yildirim T, Agildere AM, Oguzkurt L, Barutcu O, Kizilkilic O, Kocak R, Niron EA : MRI evaluation of cranial bone marrow signal intensity and thickness in chronic anemia. Eur J Radiol, 53 : 125-130, 2005.

8. Sumi M, Ichikawa Y, Katayama I, Tashiro S, Nakamura T: Diffusion-weighted MR imaging of ameloblastomas and keratocystic odontogenic tumors: differentiation by apparent diffusion coefficients of cystic lesions. Am J Neuroradiol, 29 : 18971990, 2008.

9. Moon WJ, Lee MH, Chung EC: Diffusion-Weighted Imaging with Sensitivity Encoding (SENSE) for Detecting Cranial Bone Marrow Metastases: Comparison with T1-Weighted Images. Korean J Radiol, 8: 185-191, 2007.

10. Baur A, Olaf D, Reiser M : Diffusion-weighted imaging of bone marrow : current status. Eur Radiol, 13 : 1699-1708, 2003.

11. Messiou C, Collins D, Giles S, Bono J, Bianchini D: Assessing response in bone metastases in prostate cancer with diffusion weighted MRI. Eur Radiol, 21 : 2169-2177, 2011.

12. Raya JG, Dietrich O, Reiser MF, BaurM A: Techniques for diffusion-weighted imaging of bone mar- row. Eur J Radiol, 55 : 64-73, 2005.

13. Castillo M, Arbelaez A, Smith JK, Fisher LL: Diffusionweighted MR imaging offers no advantage over routine noncontrast MR imaging in the detection of vertebral metastases. Am J Neuroradiol, 21 : 948-953, 2000.

14. Mirowitz SA, Apicella P, Reinus WR, Hammerman AM : MR imaging of bone marrow lesions: relative conspicuousness on T1-weighted, fat-suppressed T2weighted, and STIR images. Am J Roentgenol, 162 : 215-221, 1994.

15. Adachi M, Hosoya T, Haku T, Yamaguchi K, Kawanami T: Evaluation of the substantia nigra in patients with Parkinsonian syndrome accomplished using multishot diffusion-weighted MR imaging. Am J Neuroradiol, 20 : 1500-1506, 1999.

16. Herneth AM, Friedrich K, Weidekamm C, Schibany N, Krestan C, Czerny C: Diffusion weighted imaging of bone marrow pathologies. Eur J Radiol, 55 : 74-83, 2005.

17. Raya JG, Dietrich O, Reiser MF, Baur-Melnyk A : Techniques for diffusion-weighted imaging of bone marrow. Eur J Radiol, 55 : 64-73, 2005.

18. Loevner LA, Tobey JD, Yousem DM, Sonners AI, Hsu WC: MR imaging characteristics of cranial bone marrow in adult patients with underlying systemic disorders compared with healthy control subjects. Am J Neuroradiol, 23 : 248-254, 2002. 